\title{
Long-Term Effects of Bariatric Surgery on Health-Related Quality of Life: A Systematic Review
}

\author{
Roberta Sônia Rodrigues Álvares”, Maria de Fátima Haueisen Sander Diniz, \\ Ana Luisa Bagno de Almeida, Matheus Nagib Lemos Paulo, Alline Maria Rezende Beleigoli
}

Medicine Department, Federal University of Minas Gerais, Belo Horizonte, Brazil

Email address:

robertarodrigues21@yahoo.com.br (R. S. R. Álvares), mfhsdiniz@yahoo.com.br (M. de F. H. S. Diniz), analuisabalmeida@hotmail.com (A. L. B. de Almeida), nagib.matheus@yahoo.com.br (M. N. L. Paulo), abeleigoli@gmail.com (A. M. R. Beleigoli)

${ }^{*}$ Corresponding author

\section{To cite this article:}

Roberta Sônia Rodrigues Álvares, Maria de Fátima Haueisen Sander Diniz, Ana Luisa Bagno de Almeida, Matheus Nagib Lemos Paulo, Alline Maria Rezende Beleigoli. Long-Term Effects of Bariatric Surgery on Health-Related Quality of Life: A Systematic Review. Journal of Surgery. Vol. 6, No. 3, 2018, pp. 61-67. doi: 10.11648/j.js.20180603.12

Received: March 12, 2018; Accepted: April 8, 2018; Published: May 9, 2018

\begin{abstract}
Introduction: Obese patients who seek bariatric surgery (BS) have great impairment in health-related quality of life (HRQoL). Along with weight loss, BS leads to improvement in HRQoL in the short-term. However, physical, psychological and social issues that ensue after BS might impact on HRQoL in the long-term. The aim was to systematically review the literature in order to explore the impact of bariatric surgery on HRQoL of severely obese patients in the long-term. Methods: Electronic databases were searched (Pubmed/Medline, Lilacs, IBECS, Cochrane Library, SciELO) to retrieve studies of adults with BMI $\geq 35 \mathrm{~kg} / \mathrm{m}^{2}$ which assessed HRQoL five or more years after BS. Hand search of references of previous reviews was also performed. GRADE was used to assess the quality of the evidence. Results: Of the 1226 articles retrieved, nine longitudinal studies were selected. A total of 4031 patients were followed-up. Female sex was predominant in all studies. Only one study did not find improvement in HRQoL after BS. Improvement of physical aspects of HRQoL was more commonly reported than mental aspects. The quality of the evidence retrieved was rated as low mainly due to the lack of adjustment for prognostic factors that might have led to counfounding in the assessment of HRQoL and under-report of followup rates. Differences in the instruments to assess HRQoL and in the composition of control groups among the studies did not allow to perform meta-analysis. Conclusion: BS was associated with improvement in HRQoL in the long-term, particularly in physical aspects. The low quality of the studies selected points out to the need of controlled trials to better assess the long-term effects of BS on HRQoL.
\end{abstract}

Keywords: Quality of Life, Health-Related Quality of Life, Bariatric Surgery, Long-Term Effects

\section{Introduction}

The global obesity epidemic has been rapidly becoming a major public health problem [1]. Obesity is associated with an increased risk for type 2 diabetes, hypertension, dyslipidemia, cardiovascular diseases, musculoskeletal disorders, psychological stress, certain types of cancer, mortality, and affects health-related quality of life (HRQoL) [2-4]. The primary objective of all forms of obesity treatment is to improve morbidity and mortality [4]. Bariatric surgery is, currently, considered the most effective treatment to achieve sustained weight loss in patients with severe obesity $[5,6]$ and the number of individuals eligible for bariatric surgery exceeds public health care capacity for surgery [7].

Adherence to long-term follow-up after bariatric operation has been associated with better outcomes in regard to weight loss [8]. Current guidelines recommend that patients should be followed up during their entire life after bariatric surgery $[9,10]$. Along with assessment of weight loss and regain, adherence to supplements use, comorbidities, occurrence of complications and reoperations [11], evaluation of HRQoL provides a comprehensive assessment of the burden and benefits of bariatric operations. 
The World Health Organization (WHO) defines quality of life as the individuals' perception of their position in life in the context of the culture and value systems in which they live and in relation to their goals, expectations, standards and concerns [12]. Meanwhile, HRQoL encompass those aspects of overall quality of life that can be clearly shown to affect health-either physical or mental [13, 14]. Studies have shown HRQoL varies in overweight and obese patients by treatment-seeking status, and patients seeking bariatric surgery have the most impaired HRQoL [15]. Studies have demonstrated that bariatric surgery improves HRQoL in the short term [16, 17, 18]. However, changes in family, friends and employment relationships, as well as new health issues related to surgery, and potential complications might ensue after bariatric surgery. These changes might generate tension and pose special social, psychological, and lifestyle challenges to patients and comprise stressor factors in the long term ( $\geq$ five years) [19]. Furthermore, high drop-out rates after bariatric surgery $[20,21]$ make it difficult to investigate the effect of bariatric surgery on HRQoL in the long-term. Hence, the aim was to systematically review the literature in order to explore the impact of bariatric surgery on HRQoL of severely obese patients in the long-term.

\section{Methods}

For the purpose of this review, studies were eligible if they reported long-term data ( $\geq 5$ years) of adult ( $\geq 18$ years) patients submitted to bariatric operation. The exclusion criteria were: not HRQoL, not bariatric surgery, HRQoL available only for the pre-operative period, more than $50 \%$ of participants with BMI $<35 \mathrm{~kg} / \mathrm{m}^{2}$, duplicated study (multiple papers reporting data from the same study were considered as one), not longitudinal studies, reoperation, jejuno-ileal bypass surgery, and studies that evaluated HRQoL only of specific subgroups, such as those with mental disorders.

Six electronic databases were searched (Pubmed/Medline, Lilacs, IBECS, Cochrane Library, SciELO) up to May $21^{\text {st }}$, 2015. No language restrictions were applied. Research was conducted both for Mesh terms and terms in titles/abstracts that corresponded to the following strategy: "massive obesity", "severe obesity", "morbid obesity ", "abdominal obesity ", "metabolic surgery", "weight loss surgery", "bariatric surgery", "bariatric medicine", "quality of life". Hand search of the references of previous reviews was also performed.

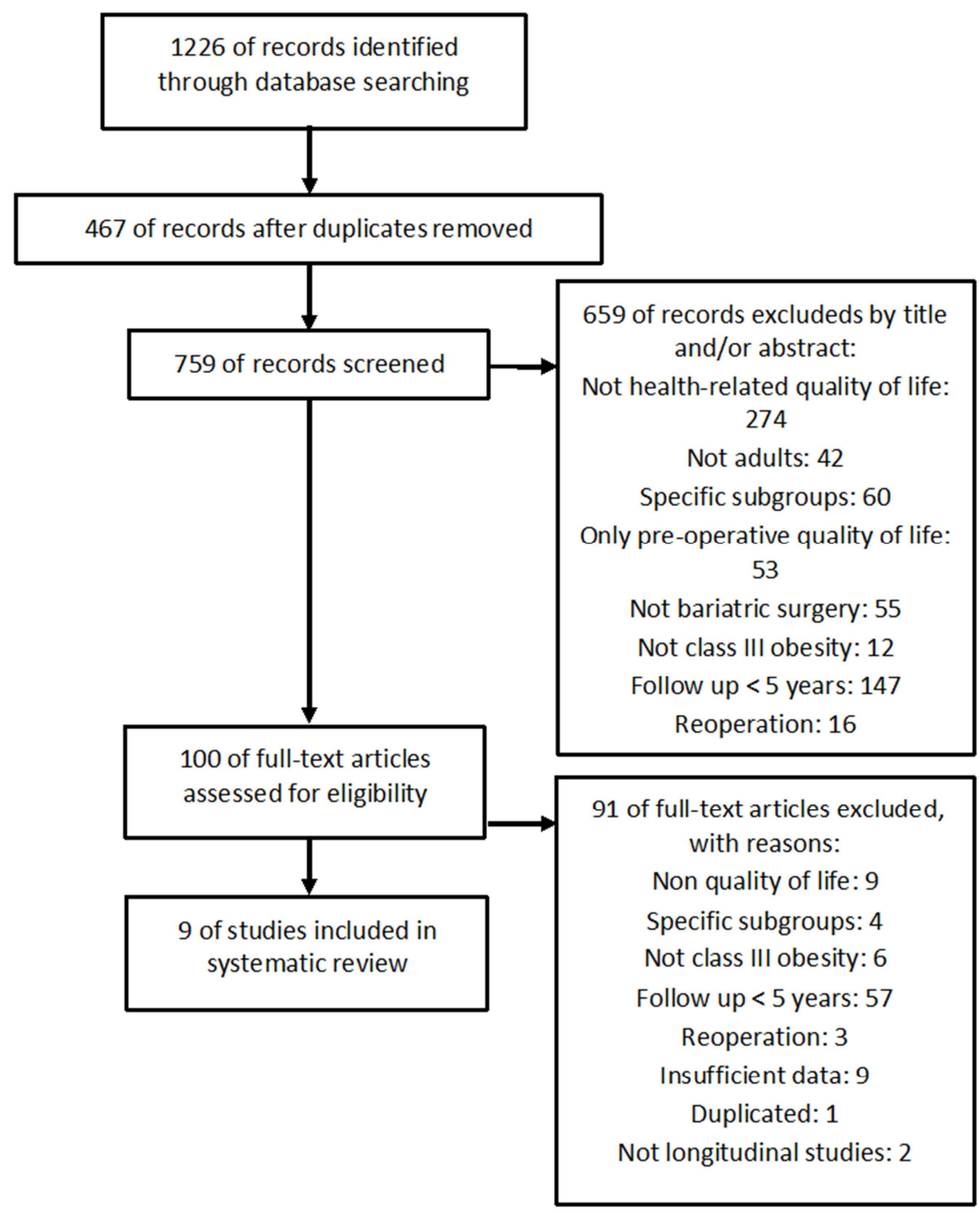

Figure 1. Literature identification strategy. 
The search strategy resulted in 1226 articles. Of these articles 785 were excluded based on the title (467 were duplicated studies, 167 did not address HRQoL, 22 did not select adults, 36 investigated disease-specific groups, 37 assessed HRQoL only in the pre-operative period, 39 were not related to bariatric surgery - three selected more than $50 \%$ of participants with BMI $<35 \mathrm{~kg} / \mathrm{m}^{2}, 13$ did not have a long-term follow-up and - one was related to reoperation). 341 articles were excluded based on abstract screening (107 did not address HRQoL, 20 did not select adults, 134 did not have a long-term follow-up, 24 investigated disease-specific groups, 16 assessed HRQoL only in the pre-operative period, 16 were not related to bariatric surgery, nine did not assessed class III obesity and 15 were related to reoperation). Full text of the remaining 100 articles was read with 91 of them being excluded (nine did not address HRQoL, 57 did not have a long-term follow-up, four investigated disease-specific groups, six did not assess class III obesity, three were related to reoperation, nine had insufficient data and one was duplicated, two were not longitudinal studies). A summary flow chart of the literature identification strategy is presented in Figure 1.

Two reviewers (RSRA and ALBA) independently carried out the selection of the studies according to the pre-defined eligibility criteria. Any disagreement between them was evaluated by two other authors (AMRB and MFHSD).

The assessment of the quality of the evidence retrieved by the systematic review was performed according to the GRADE approach to observational studies, which proposes the rating of the risk of bias (low, serious or very serious) of individual studies in regard to the appropriateness of (1) the control population and (2) measures of the outcome both in the intervention and control groups, (3) measurement of prognostic factors that are possible to influence on the outcome and (4) adjustment for them, (5) rates of follow-up and (6) the magnitude of the effect of the intervention [22]. Rating of the appropriateness of the control population took into account whether the comparison was undertaken both over time (before and after surgery) and between groups which were and were not (waiting list, no treatment or nonsurgical treatment) submitted to surgery. Additionally, the recruitment of the control and intervention group from the same population was considered as an adequate composition of the control group. The use of the same HRQoL instrument in control and intervention groups and follow-up rates superior to $50 \%$ were the criteria applied to rate the risk of bias related to measures of the outcome and follow-up rates [5]. Weight loss, resolution of physical and psychosocial comorbidities, postoperative complications, re-interventions and use of medications were considered as important prognostic factors to measure and control for. The lack of either measurement of these factors or adjustment of HRQoL results for them led to an increase in the risk of bias according to prespecified criteria. Improvement of both physical and mental components of HRQoL or report of improvement by at least $75 \%$ of the participants were used as criteria to rate the magnitude of the effect as high.

\section{Results}

All studies included in the review are longitudinal with a total of 4031 patients followed-up. Female sex was predominant in all studies (Table 1). Most of the studies did not report race of the participants. Among those which did, white race was predominant $(96 \%)$ in Adams et al. (2012) [21], and black race (58\%) in Velcu et al. (2005) [23]. Besides differences regarding the instrument used to assess HRQoL, the form of application of the instrument also varied among studies. Face-to-face [24-27], face-toface or telephone [21, 23], face-to-face, mail or telephone [28] have been reported. Most studies have applied Bariatric Analysis and Reporting Outcome System (BAROS) (54.5\%) and Study 36-Item Short-Form Health Survey (SF-36) (45.4\%) to assess HRQoL. One study have used a general and a specific HRQoL instruments [28]. Surgical intervention was laparoscopic in five studies [24, 26-29]. Other characteristics of the studies retrieved are depicted in Table 1.

Table 1. Characteristics of the included studies.

\begin{tabular}{|c|c|c|c|c|c|c|c|}
\hline \multirow{2}{*}{ Study } & \multirow{2}{*}{ Total Number of Patients } & \multirow{2}{*}{ Origin } & \multirow{2}{*}{ Female (\%) } & \multicolumn{2}{|c|}{ Age at baseline } & \multicolumn{2}{|c|}{ BMI at baseline } \\
\hline & & & & SG & CG & SG & $\mathbf{C G}$ \\
\hline Kalfarentzos et al., 2001 & 35 & Greece & 77.0 & $31.6^{*}$ & & $44.1 *$ & \\
\hline Weiner et al., 2003 & 984 & Germany & 85.9 & $38.4 *$ & & $47.4 *$ & \\
\hline Velcu et al., 2005 & 41 & USA & 89.0 & $32.4 *$ & & $53.4^{*}$ & \\
\hline Pasnik et al., 2005 & 86 & Poland & 72.3 & $41.0 *$ & & $51.3 *$ & \\
\hline Karlsson et al., 2007 & 1276 & Sweden & -- & $47.0 *$ & $48.4 *$ & $41.9 *$ & $39.9 *$ \\
\hline Suter et al., 2011 & 379 & Switzerland & 74.4 & $39.4 *$ & --- & $46.3 *$ & 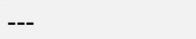 \\
\hline Aftab et al., 2014 & 184 & Norway & 75.0 & $38.0^{*}$ & & $46^{*}$ & \\
\hline García et al., 2015 & 44 & Spain & 77.3 & $39.6^{*}$ & & $51.3 *$ & $\operatorname{ar} ; 36.7 *-5$ years \\
\hline
\end{tabular}

Table 1. Continued.

\begin{tabular}{|c|c|c|c|c|}
\hline Study & Surgical Technique & QoL Instrument & Follow-up (years) & Improvement in QoL \\
\hline Kalfarentzos et al., 2001 & BPD & BAROS & 5.0 & No \\
\hline Weiner et al., 2003 & LAGB & SF-36; BAROS & $8.2^{+}$ & Yes \\
\hline
\end{tabular}




\begin{tabular}{lllll}
\hline Study & Surgical Technique & QoL Instrument & Follow-up (years) & Improvement in QoL \\
\hline Velcu et al., 2005 & RYGB & SF-36 & 5.0 & Yes \\
Pasnik et al., 2005 & BPD & BAROS & Preoperative, $5.0-6.0^{\#}$ & Yes \\
Karlsson et al., 2007 & BPD; LAGB; RYGB & Current Health Scale & $6.0-10.0^{\#}$ & Yes \\
Suter et al., 2011 & RYGB & BAROS & $5.0-7.0^{+}$ & Yes \\
Adams et al., 2012 & RYGB & SF-36; IWQOL-Lite & $5.8^{+}$ & Yes \\
Aftab et al., 2014 & RYGB & SF-36; Obesity-related Problems scale & $5.2^{*}$ & Yes \\
García et al., 2015 & BPD & BAROS & 5.0 & Yes \\
\hline
\end{tabular}

BMI: Body mass index; Qol: Quality of life; SG: Surgical Group; CG: Control Group; RYGB: Roux-en-Y Gastric Bypass; BPD: Biliopancreatic Diversion; LAGB: Laparoscopic Adjustable Gastric Banding; PS: Pre Surgical; QoL: Quality of Life; BAROS: Bariatric Analysis and Reporting Outcome System; SF-36: Short-Form Health Survey; IWQOL-Lite: Impact of Weight Quality of Life

*: mean; +: median; \#: range

Control groups characteristics differed widely among the studies. Control groups were comprised of obese participants waiting for bariatric surgery [23, 26, 27], obese participants either undergoing medical treatment [30] or without any treatment [21]. Likewise, surgical procedures varied importantly among studies. Additionally, individual studies investigated the effects of different types of bariatric operations on HRQoL, as shown in Table 1. Although differences in the instruments to assess HRQoL were noted among the studies (Table 1), they did not differ between the intervention and control groups within individual studies. In general, the studies performed appropriate measures of prognostic factors both in the intervention and control groups. However lack of adjustment for these factors was common $[23,25,26,27,30]$. Most of the studies reported follow-up rates superior to $50 \%$, but data on this issue was missing in two studies $[27,29]$. Taking all these issues into account, the quality of the evidence retrieved by this review as low (Table 2).

Table 2. Quality of the evidence of the included studies.

\begin{tabular}{|c|c|c|c|c|c|c|c|}
\hline \multirow{2}{*}{ Study } & \multicolumn{2}{|l|}{ Control population } & \multicolumn{2}{|c|}{ Exposure and outcome measurements } & \multicolumn{2}{|c|}{ Control for confounding factors } & \multirow{2}{*}{$\begin{array}{l}\text { Follow-up } \\
\text { Complete }\end{array}$} \\
\hline & Control population & Selection & No differences & Similar surveillance & Accurate measurement & Matching & \\
\hline Kalfarentzos et al., 2001 & $\mathrm{XX}$ & NA & $\mathrm{X}$ & NA & $\mathrm{XX}$ & XXX & $\mathrm{X}$ \\
\hline Weiner et al., 2003 & $\mathrm{XXX}$ & NA & $\mathrm{XX}$ & NA & $\mathrm{X}$ & $\mathrm{XX}$ & $\mathrm{X}$ \\
\hline Velcu et al., 2005 & $\mathrm{XXX}$ & NA & $\mathrm{X}$ & NA & $\mathrm{XX}$ & XXX & $\mathrm{X}$ \\
\hline Pasnik et al., 2005 & $\mathrm{X}$ & $\mathrm{X}$ & $\mathrm{X}$ & NA & $\mathrm{XX}$ & $\mathrm{XXX}$ & $\mathrm{XXX}$ \\
\hline Karlsson et al., 2007 & $\mathrm{X}$ & $\mathrm{X}$ & NA & $\mathrm{X}$ & NA & $\mathrm{XXX}$ & $\mathrm{XXX}$ \\
\hline Suter et al., 2011 & $\mathrm{XX}$ & NA & $\mathrm{XX}$ & $\mathrm{X}$ & $\mathrm{X}$ & $\mathrm{XX}$ & $\mathrm{XXX}$ \\
\hline Adams et al., 2012 & $\mathrm{X}$ & $\mathrm{X}$ & $\mathrm{X}$ & $\mathrm{XX}$ & $\mathrm{X}$ & $\mathrm{X}$ & $\mathrm{XX}$ \\
\hline Aftab et al., 2014 & $X X$ & $\mathrm{X}$ & $\mathrm{X}$ & $\mathrm{X}$ & $\mathrm{X}$ & XXX & $\mathrm{X}$ \\
\hline Garcial et al., 2015 & $\mathrm{XX}$ & NA & $\mathrm{X}$ & $\mathrm{X}$ & $\mathrm{X}$ & $\mathrm{XXX}$ & $\mathrm{XXX}$ \\
\hline
\end{tabular}

X - Low Risk of Bias; XX - Serious Risk of Bias; XXX Very Serious Risk of Bias; NA - not available

Control population: Control population (control of time and group); Selection: Selection of exposed and unexposed in cohort studies not from different populations; No differences: No differences in measurement of exposure ( different types of operation, different types of treatment in the control group, BAROS recall bias); Similar surveillance: Similar surveillance for outcome in exposed and unexposed in cohort studies (same instruments were used in the experimental and control groups); Accurate measurement: Accurate measurement of all known prognostic factors; Matching: Adequate match for prognostic factors and/or lack of adjustment in statistical analysis; Follow-up: Complete follow-up

According to pre-defined criteria, four of the nine studies $[23-25,27]$ reported a high magnitude of the effect of bariatric surgery on quality of life. Only one found that HRQoL was reduced after surgery [25]. This study selected only patients submitted to vertical banded gastroplasty. Most of the studies, however, observed that improvement was not consistent among all aspects of HRQoL. According to Velcu et al. (2005) [23], SF-36 scores have improved after gastric bypass. Yet, no significant difference was noted between the 5-year postoperative group and the U.S. norm. In Karlsson et al. (2007) [30] study, at 10 years net gains were noted in all HRQoL domains compared to baseline. Surgical group presented better outcomes on current health perceptions, social interaction, psychosocial functioning and depression, whereas no significant differences were found for overall mood and anxiety. A detailed description of HRQoL results per article is presented in table 3 .

Table 3. Health-related Quality of Life Results.

\begin{tabular}{|c|c|c|c|}
\hline \multirow{2}{*}{ Article } & \multirow{2}{*}{ Comparison Group } & \multicolumn{2}{|c|}{ Qol Instrument and Outcome } \\
\hline & & $\mathbf{C G}$ & SG \\
\hline $\begin{array}{l}\text { Kalfarentzos et } \\
\text { al., } 2001\end{array}$ & $\begin{array}{l}\text { Same patients at } 5 \\
\text { postoperative years }\end{array}$ & ----- & $\begin{array}{l}\text { BAROS: No improvement in QoL. At } 5 \text { years } \\
\text { postoperatively, none of the patients were in the } \\
\text { very good or excellent categories }\end{array}$ \\
\hline Weiner et al., & Same patients at 8 & ---- & Using the SF-36, the changes were small; however, \\
\hline
\end{tabular}




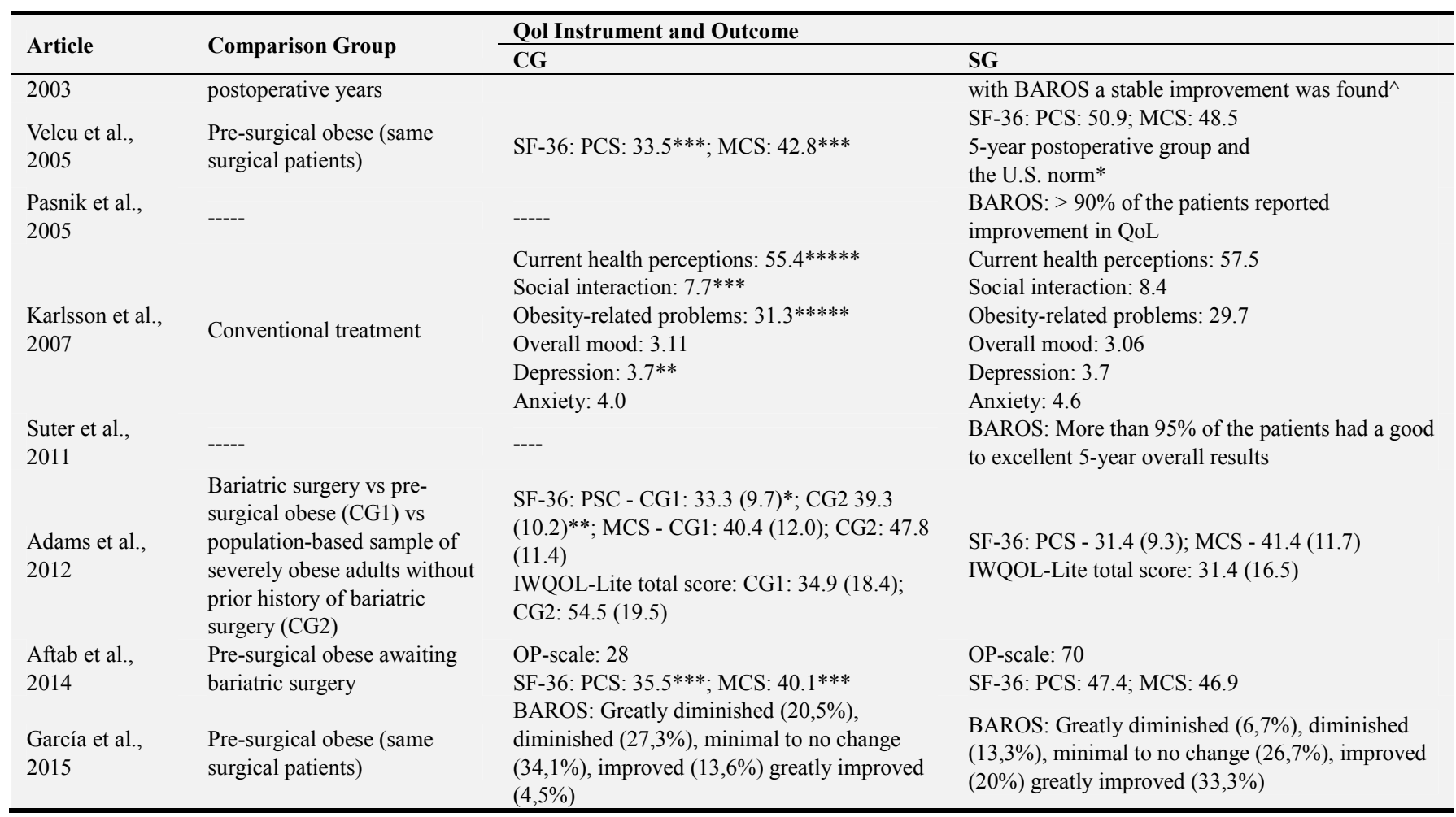

CG: Control Group; SG: Surgical Group; PCS: Physical Component Score; MCS: Mental Component Score; PF: Physical functioning; RP: Role-physical; BP: Bodily pain; GH: General health; VT: Vitality; SF: Social functioning; RE: Role-emotional; MH: Mental health; BAROS: Bariatric Analysis and Reporting Outcome System; SF-36: Short-Form Health Survey; IWQOL-Lite: Impact of Weight Quality of Life; OP-Scale: Obesity-related Problems scale

Maximum score of greatly improved in BAROS: +3; OP-Scale: range of scores 0 (no impairment) to 100 (maximum impairment); SF-36: range of scores 0 100 with higher scores indicating better health status, physical component score 12-69 with 69 being best, mental component score 8-73 with 73 being best; IWQOL-Lite total score: range of scores $0-100$, with 100 being best and normative mean of 94.7

${ }^{\wedge}$ no numeric results were provided in the reference paper

$* \mathrm{p}>.05 * * \mathrm{p}<.05 * * * \mathrm{p}<.01 * * * * \mathrm{p}<.001 * * * * * \mathrm{p}<.0001$

\section{Discussion}

The great majority of the studies retrieved by this systematic review reported that bariatric surgery was associated with long-term improvement in HRQoL. Actually, improvement of physical aspects of HRQoL was more common than mental aspects in the long-term after bariatric surgery. These results are consistent with recent reviews [18, $31,32]$. False expectations that bariatric surgery does not demand long-term maintenance of healthy lifestyle habits in order to control weight and comorbidities, as well as changes in social ties after surgery [19], might explain the lack of improvement in mental aspects of HRQoL. These results highlight the need for adjunctive interventions targeting mental health and social and environmental factors to facilitate improvement in all domains of HRQoL following bariatric surgery [18]. Furthermore, Andersen et al. (2015) [33] showed impaired HRQoL prior to surgery and much of initial HRQol improvements were maintained over the long term.

Both disease-specific and generic HRQoL instruments were used in the studies included in this review. Ballantyne (2003) [34] recommended that studies addressing the issue of HRQoL and obesity should have at least one generic and specific HRQoL questionnaire for better HRQoL information and to facilitate comparisons of results across studies. BAROS, which is a questionnaire used to evaluate the results of surgical treatment of morbid obesity [35], was the diseasespecific instrument most commonly applied among the studies retrieved in the review. Recall bias may have occurred in studies which applied BAROS only in the postoperative period with inherent comparison to conditions in the pre-operative period. On the other hand, with the use of generic instruments such as SF- 36, the HRQoL is assessed both, at pre and post-operative time, by each of eight domains (limitations in physical activities, social activities usual role activities, bodily pain, general mental health, vitality, and general health perception) [36], and it is possible to evaluate the HRQoL both at the time of the pre-operative and post-operative [37]. However, since it is a generic healthrelated HRQoL measurement, in contrast with BAROS which is a disease specific instrument developed to study samples of obese patients [38], SF-36 may not capture all the changes that occur with the obese population who undergo bariatric surgery.

The GRADE also suggests the assessment of imprecision, inconsistency and risk of bias of the evidence retrieved by systematic reviews with meta-analysis. Like Andersen et al. (2015) [33], meta-analysis of the data would not be 
appropriate due to substantial differences between the studies in regard to design and use of multiple instruments of HRQoL that are not comparable, these criteria were not evaluated.

The quality of the evidence retrieved was considered as low, particularly due to under-report of follow-up rates. Results of studies that did not take follow-up rates into account might have been biased since HRQoL might differ between those who were and were not followed. Additionally, failure to account for an imbalance between surgical and control groups in relation to factors that might influence HRQoL, such as the presence of comorbidities and the use of medications at baseline and changes over the follow-up, might have introduced bias to the studies. Moreover, great differences in control groups characteristics, surgical procedures and types of HRQoL instruments lead to high heterogeneity among the studies, which makes it difficult to compare the results. Other limitations include the lack of pre-operative scores in the surgical group [26], the lack of designated control groups [28], and the small study population [29]. A further limitation of this review is that none of the included studies met all GRADE quality criteria.

The investigation of factors, such weight loss [30], associated with HRQoL after bariatric surgery gives some clues to health professionals to aspects to pay attention to in bariatric surgery patients' care, in order to achieve favorable outcomes regarding the long-term HRQoL.

The high proportion of good results in comparison to poor results after surgery found in this review raises suspicion of publication bias, since one study showed no improvement or decrease in QoL and eight showed an improvement in QoL. Publication bias occurs when the outcome of a study influences the decision whether to publish it or not. Literature reviews on support for a hypothesis can be biased if the original literature is contaminated by publication bias. Although has not been investigate the occurrence of this bias by statistical methods, the search included grey literature evidence, which is more prone to contain negative results.

\section{Conclusion}

In general, bariatric surgery was associated with improvement in HRQoL in the long-term, particularly in physical aspects. This suggests that psychosocial interventions are essential in the long-term care after bariatric surgery. The low quality of the studies selected points out that future research should include randomized trials, make clear report of follow-up rates and control for prognostic factors such as weight loss, resolution of physical and psychosocial comorbidities, postoperative complications, reoperations and drug use.

\section{Acknowledgements}

This study is supported by Brazilian public agencies Conselho Nacional de Desenvolvimento Científico e Tecnológico (CNPq), Fundação de Amparo à Pesquisa do
Estado de Minas Gerais (FAPEMIG), Pró Reitoria de Pesquisa da Universidade Federal de Minas Gerais and Coordenação de Aperfeiçoamento de Pessoal de Nível Superior (CAPES). The number of approval of the project by the ethics comitee of the Federal Univesity of Minas Gerais is CAAE - 13899013.4.0000.5149.

\section{Conflict of Interest}

All the authors do not have any possible conflicts of interest.

\section{References}

[1] Raoof M, Näslund I, Rask E, Karlsson J, Sundbom M, Edholm D, et al. Health-Related Quality-of-Life (HRQoL) on an Average of 12 Years After Gastric Bypass Surgery. Obes Surg. 2015; 25 (7):1119-27.

[2] Picot J, Jones J, Colquitt JL, Gospodarevskaya E, Loveman E, Baxter L, et al. The clinical effectiveness and costeffectiveness of bariatric (weight loss) surgery for obesity: a systematic review and economic evaluation. Heal Technol Assess. 2009; 13 (41):1-190, 215-357.

[3] Costa RCN, Yamaguchi N, Santo MA, Riccioppo D, PintoJunior PE. Outcomes on Quality of Life, Weight Loss, and Comorbidities After Roux-En-Y Gastric Bypass. Arq Gastroenterol. 2014; 51 (3):165-70.

[4] Sarwer DB, Spitzer JC, Wadden TA, Rosen RC, Mitchell JE, Lancaster K, et al. Sexual functioning and sex hormones in persons with extreme obesity and seeking surgical and nonsurgical weight loss. Surg Obes Relat Dis. 2013; 9 (6):997-1007.

[5] Buchwald H, Avidor Y, Braunwald E, Jensen MD, Pories W, Fahrbach K, et al. Bariatric surgery. A Systematic Review and Meta-analysis. JAMA. 2004; 292 (14):1724-37.

[6] Mancini MC. Bariatric surgery - An update for the endocrinologist. Arq Bras Endocrinol Metab. 2014; 58 (9):875-88.

[7] Ahmad A, Laverty AA, Aasheim E, Majeed A, Millett C, Saxena S. Eligibility for bariatric surgery among adults in England: analysis of a national cross-sectional survey. JRSM Short Rep. 2013; 5 (1):1-6.

[8] Gould JC, Beverstein G, Reinhardt S, Garren MJ. Impact of routine and long-term follow-up on weight loss after laparoscopic gastric bypass. Surg Obes Relat Dis. 2007; 3 (6):627-30.

[9] Mechanick JI, Youdim A, Jones DB, Timothy Garvey W, Hurley DL, Molly McMahon M, et al. Clinical practice guidelines for the perioperative nutritional, metabolic, and nonsurgical support of the bariatric surgery patient--2013 update. Surg Obes Relat Dis. 2013; 9 (2):159-91.

[10] Fried M, Hainer V, Basdevant A, Buchwald H, Deitel M, Finer N, et al. Interdisciplinary European guidelines for surgery for severe (morbid) obesity. Vol. 17, Obesity Surgery. 2007. p. $260-70$.

[11] Oria HE, Moorehead MK. Updated Bariatric Analysis and Reporting Outcome System (BAROS). Surg Obes Relat Dis. 2009; 5 (1):60-6. 
[12] WHOQOL Group. What quality of life? The WHOQOL Group. World Health Organization Quality of Life Assessment. World Health Forum. 1996; 17 (4):354-6.

[13] Centers for Disease Control and Prevention. Measuring healthy days. Population Assessment of Health-Related Quality of Life. Health Care. 2000. 1-40 p.

[14] Selim AJ, Rogers W, Fleishman JA, Qian SX, Fincke BG, Rothendler JA, et al. Updated U.S. population standard for the Veterans RAND 12-item Health Survey (VR-12). Qual Life Res. 2009; 18 (1):43-52.

[15] Risstad H, Sovik TT, Hewitt S, Kristinsson JA, Fagerland MW, Bernklev T, et al. Changes in Health-Related Quality of Life After Gastric Bypass in Patients With and Without Obesity-Related Disease. Obes Surg. 2015; 25 (12):2408-16.

[16] Oh SH, Song HJ, Kwon JW, Park DJ, Lee YJ, Chun H, et al. The improvement of quality of life in patients treated with bariatric surgery in Korea. J Korean Surg Soc. 2013; 84 (3):131-9.

[17] Dziurowicz-Kozlowska A, Lisik W, Wierzbicki Z, Kosieradzki M. Health-related quality of life after the surgical treatment of obesity. J Physiol Pharmacol. 2005; 56 (Suppl 6):127-34.

[18] Hachem A, Brennan L. Quality of Life Outcomes of Bariatric Surgery: A Systematic Review. Obes Surg. 2016; 26 (2):395409 .

[19] Bocchieri LE, Meana M, Fisher BL. Perceived psychosocial outcomes of gastric bypass surgery: A qualitative study. Obes Surg. 2002; 12 (6):781-8.

[20] De Zwaan M, Lancaster KL, Mitchell JE, Howell LM, Monson N, Roerig JL, et al. Health-related quality of life in morbidly obese patients: Effect of gastric bypass surgery. Obes Surg. 2002; 12 (6):773-80.

[21] Adams TD, Davidson LE, Litwin SE, Kolotkin RL, LaMonte MJ, Pendleton RC, et al. Health Benefits of Gastric Bypass Surgery after 6 years. JAMA. 2012; 308 (11):1122-31.

[22] Guyatt GH, Oxman AD, Vist G, Kunz R, Brozek J, AlonsoCoelho P, et al. GRADE guidelines: 4. Rating the quality of evidence - Study limitations (risk of bias). J Clin Epidemiol. 2011; 64 (4):407-15.

[23] Velcu LM, Adolphine R, Mourelo R, Cottam DR, Angus LDG. Weight loss, quality of life and employment status after Roux-en-Y gastric bypass: 5-year analysis. Surg Obes Relat Dis. 2005; 1 (4):413-6.

[24] Suter M, Donadini A, Romy S, Demartines N, Giusti V. Laparoscopic Roux-en-Y gastric bypass: significant long-term weight loss, improvement of obesity-related comorbidities and quality of life. Ann Surg. 2011; 254 (2):267-73.

[25] Kalfarentzos F, Kechagias I, Soulikia K, Loukidi A, Mead N. Weight loss following vertical banded gastroplasty: Intermediate results of a prospective study. Obes Surg. 2001; $11(3): 265-70$.
[26] Aftab H, Risstad H, Søvik TT, Tomm Bernklev PD, Hewitt S, Kristinsson JA, et al. Five-year outcome after gastric bypass for morbid obesity in a Norwegian cohort. Surg Obes Relat Dis. 2014; 10 (1):71-8.

[27] García AMA, Márquez MF, Carreño TP, Alcaraz Garcia AM, Ferrer Marquez M, Parron Carreno T. Quality of life in obese patients and change after bariatric surgery medium and long term. Nutr Hosp. 2015; 31 (5):2033-46.

[28] Weiner R, Blanco-Engert R, Weiner S, Matkowitz R, Schaefer L, Pomhoff I. Outcome after Laparoscopic Adjustable Gastric Banding -8 Years Experience. Obes Surg. 2003; 13 (3):42734.

[29] Pasnik K, Krupa J, Stanowski E. Vertical banded gastroplasty: 6 years experience at a center in Poland. Obes Surg. 2005; 15 (2):223-7.

[30] Karlsson J, Taft C, Rydén A, Sjostrom L, Sullivan M. Tenyear trends in health-related quality of life after surgical and conventional treatment for severe obesity: the SOS intervention study. Int J Obes (Lond). 2007; 31 (8):1248-61.

[31] Lindekilde N, Gladstone BP, Lubeck M, Nielsen J, Clausen L, Vach W, et al. The impact of bariatric surgery on quality of life: a systematic review and meta-analysis. Obes Rev. 2015; $16(8): 639-51$.

[32] Jumbe S, Bartlett C, Jumbe SL, Meyrick J. The effectiveness of bariatric surgery on long term psychosocial quality of life A sistematic review. Surg Obes Relat Dis. 2016; 10 (3):22542 .

[33] Andersen JR, Aasprang A, Karlsen T-I, Karin Natvig G, Våge V, Kolotkin RL. Health-related quality of life after bariatric surgery: a systematic review of prospective long-term studies. Surg Obes Relat Dis. 2015; 11 (2):466-73.

[34] Ballantyne GH. Measuring Outcomes following Bariatric Surgery: Weight Loss Parameters, Improvement in Co-morbid Conditions, Change in Quality of Life and Patient Satisfaction. Obes Surg. 2003; 13 (6):954-64.

[35] Oria HE, Moorehead MK. Bariatric Analyses and Reporting Outcome System (BAROS). Obes Surg. 1998; 8:487-99.

[36] Ware JE, Snow KK, Kosinski M, Gandek B. SF-36 Health Survey Manual and Interpretation Guide. Bost New Engl Med Cent. 1993; 1 v. (various pagings).

[37] O'Brien PE, Dixon JB, Brown W, Schachter LM, Chapman L, Burn AJ, et al. The laparoscopic adjustable gastric band (LapBand?): A prospective study of medium-term effects on weight, health and quality of life. Obes Surg. 2002; 12 (5):652-60

[38] Khawali C, Ferraz MB, Zanella MT, Ferreira SRG. Evaluation of quality of life in severely obese patients after bariatric surgery carried out in the public healthcare system. Arq Bras Endocrinol Metab. 2012; 56 (1):33-8. 